\title{
CONCEPCIÓN: EL TRABAJADOR DEL COMERCIO INFORMAL DE CALLE. \\ La producción efímera del espacio en la crisis social.
}

Concepción: $O$ trabalhador do comercio informal de rua. A produção efêmera do espaço na crise social.

Concepción: the informal streetseller.

The ephemeral production of space in the social crisis.

\section{Mônica Virginia de Souza}

Becaria, CONICYT

Doctorado $\odot$ en el Doctorado en Arquitectura

y Estudios Urbanos de la Pontificia Universidad

Católica de Chile - Docente en la Facultad

de Arquitectura y Arte de la Universidad del

Desarrollo.

monica.vs@uol.com.br

https://orcid.org/0000-0003-1258-275X

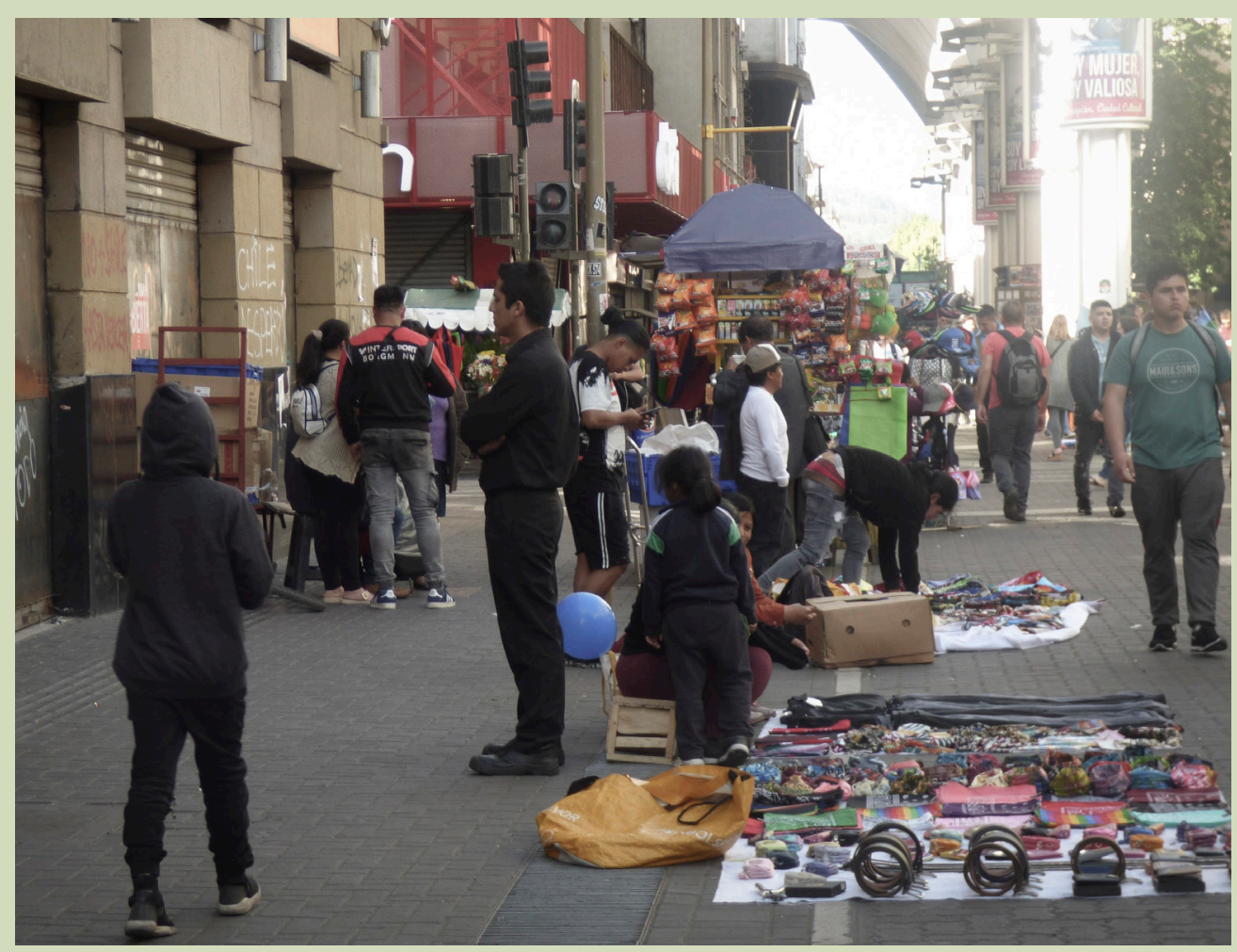

Proyecto:

Comisión Nacional de Investigación

Científica y Tecnológica (CONICYT)

Folio 63130204

- Programa de

Doctorado en

Arquitectura y Estudios

Urbanos de la Pontificia Universidad Católica de Chile. 


\section{RESUMEN}

Las ciudades modernas presentan un gran problema: el mito del poder de la tecnocracia (Lefebvre) en donde la producción basada en normas institucionales y reglas (estándar) de convivencia dan como resultado espacios llenos de contradicciones (algunos tangibles y otros no). Un ejemplo de antítesis a esa ciudad tecnocrática puede ser la praxis del comercio informal de calle, el que históricamente ha producido espacios efímeros que, contradictoriamente al sentido ontológico, es perenne - ha resistido a la represión y opresión - y logrado mantener su quehacer, así como el derecho de ocupar y habitar la ciudad. En ese sentido, el estallido social del 18 de octubre, en plena primavera chilena abre luces sobre diferentes iniciativas en dirección a las formas de representación social y reapropiación de los espacios sociales y urbanos, en un momento en que ese deseo de la sociedad es personificado por miles de manifestantes en las calles reivindicando dignidad, justicia y derechos. A partir de ese escenario, la propuesta de este artículo es develar las acciones del trabajador del comercio informal de calle en la producción efímera del espacio, cuyo resultado indica un instinto político, una intuición y sagacidad en su carácter, que le ha ayudado a traspasar los obstáculos cotidianos, permitiéndole resistir y permanecer en la ciudad. Para este estudio se presenta la experiencia de los trabajadores del comercio informal de calle de Concepción Chile, la tercera más grande e importante del país, en que el número de esos trabajadores es expresivo y su comportamiento ha llamado la atención durante el estallido social.

Palabras clave: producción efímera del espacio, comercio informal, trabajador callejero, espacio urbano, estallido social.

\section{RESUMO}

As cidades modernas apresentam um grande problema: o mito do poder da tecnocracia (Lefebvre) onde a produção baseada em normas institucionais e regras (padrão) resultam em espaços repletos de contradições (alguns tangíveis e outros não). Um exemplo antíteses de essa cidade tecnocrática pode ser a práxis do comercio informal de rua, que historicamente há produzido espaços efêmeros, que contraditoriamente ao sentido antológico, é perene - tem resistido a opressão e repressão - e conseguido manter seu trabalho, assim como o direito de ocupar e habitar a cidade. Nesse sentido, o "despertar social" de 18 de outubro, em plena primavera chilena aclaram sobre diferentes inciativas em direção as formas de representação social e reapropriação dos espaços sociais e urbanos, em um momento em que esse desejo da sociedade é personificada por milhares de manifestantes nas ruas reivindicando dignidade, justiça e direitos. A partir desse cenário, a proposta deste artigo é mostrar as ações do comercio informal de rua no que diz respeito a produção efêmera do espaço, cujo resultado indica um instinto político, uma intuição e sagacidade em seu caráter, que os têm ajudado a traspassar os obstáculos cotidianos, permitindo-os resistir e permanecer na cidade. Para esse estudo, se apresenta a experiência dos trabalhadores do comercio informal de rua de Concepción, Chile, a terceira maior e mais importante cidade do país, a qual o número destes trabalhadores é expressivo e seu comportamento tem chamado atenção durante as manifestações sociais.

Palavras chave: produção efêmera do espaço, comercio informal, trabalhador do espaço público, espaço urbano, revolução social.

\section{ABSTRACT}

Modern cities have a great problem: the myth of the power of technocracy (Lefebvre), where the production based on the institutional norms and rules (standard) of coexistence results in spaces full of contradictions (some tangible and others not so much). An example of an antithesis to that technocratic city may be the praxis of informal street trade that has historically produced ephemeral spaces, which at odds with the ontological sense, is perennial, i.e.., has resisted repression and oppression, and has also managed to maintain its functioning and right to occupy and inhabit the city. Thus, the popular revolution of the Chilean spring (October 18) has shed light on many different initiatives regarding the forms of social representation and (re)appropriation of social and urban spaces, at a time when the desire of society is personified by thousands of protesters on the streets demanding dignity, justice and social rights. Facing this situation, the proposal of this article is to present the actions of the informal street trade work in the ephemeral production of the space, whose result indicates a political instinct, an intuition and sagacity in its nature that has helped it to overcome the daily barriers, allowing it to resist and remain in the city. For this study, the experience of informal street traders in the city of Concepción, Chile, the third largest and most important in the country, is presented, where the number of these workers is telling and their behavior has attracted attention during the social revolution.

Keywords: ephemeral urban space, space production, street trade, informal street trader, social revolution. 


\section{INTRODUCCIÓN}

1 Cuando Carlos Ruiz (2019: 11) dijo que: "el neoliberalismo está tan presente en nuestra cotidianidad que ni siquiera lo advertimos en tanto ideología, como si fuera una fuerza natural". Nadie en Chile, ni partidos políticos (izquierda y derecha), gobierno, sindicatos y ni empresarios imaginaban lo que estaría por venir. Las protestas surgieron de una extensa lista de demandas sociales incluyendo desde el fin de las Administradores de los Fondos de Pensiones (AFP) y TAG o Televía (dispositivo que permite el sistema de cobro de vehículos que utilizan las autopistas de Santiago), del sistema privado de salud y educación, aumento del sueldo mínimo hasta las demandas puntuales como la inclusión de minorías sociales en los programas de gobiernos, en las pautas de discusión parlamentarias, en políticas públicas, medio ambiente, nueva constitución, entre otras tantas. La ausencia de banderas de partidos políticos y de sindicatos puede tener diferentes interpretaciones: desmovilización de la izquierda y miedo de las elites (pequeño burguesa) que hacen parte del ala progresista, falta de sintonía entre los sindicatos, desconexión entre partidos políticos y población que toma las calles de las principales ciudades chilenas de norte al sur.
El estallido social en Chile dio inicio a una de las más grandes revoluciones populares en América Latina del siglo XXI. Los motivos de esa manifestación están en los resultados de la continuada expoliación contra la mayoría de los chilenos que han sobrevivido bajo la economía neoliberal (implantada desde la dictadura militar de Augusto Pinochet en septiembre de 1973), cuyo propósito como doctrina es posicionar ese modelo económico en el centro de la condición humana y reorganizar la sociedad de acuerdo con las necesidades del mercado global. El estallido social ${ }^{1}$ de la primavera chilena de 2019 enmarca puntos que podrían servir como temas de reflexión sobre cómo lidiar con las consecuencias pos tragedias naturales y sociales, un país que ha soportado eventos telúricos de gran magnitud y una dictadura que ha victimizado a miles de chilenos. En ambos casos, la recuperación dependerá de esfuerzos de las autoridades públicas, benevolencia y de la ayuda colectiva necesaria para volver a la "normalidad" y felicidad, que en efecto se relaciona con un horizonte de todos los aspectos del bienestar. Eso significa que la felicidad (epistemológica) "no es un término finito, debe ser con relación al conjunto de las aspiraciones humanas" (Ricouer, P., 1986, pp. 84-85), un afán advenido de algo imprescindible para llevar una vida digna. Entre las palabras de orden que definen esta masiva movilización social están dignidad y derechos de miles de chilenos que desde 1973 han sido prescindidos en razón de la ilegitimidad sistémica, crisis de representatividad política y expoliación salvaje de trabajadores, de clase media y pobres. El despojo social, del espacio urbano fue excluido por la economía productiva en expansión, responsable por el crecimiento territorial desigual, que revela el fondo turbio de la existencia miserable y de libertad malograda como consecuencia de la injusticia social.

La revolución popular provoca el "desmoronamiento" de la ciudad para recuperarla brevemente. Mientras no sea posible, vale resignificarla a partir de acciones representativas vinculadas a los derechos sociales legítimos en todo lugar. Las acciones (polémicas) de los manifestantes se presentan como negación de ese Gobierno, de esa política y de esa autoridad policial fundada en la injusticia, en la mezquindad y en la opresión. En las marchas están las banderas de los pueblos originarios, la oficial del país, las totalmente negras y las banderas de las minorías, no hay banderas de partidos políticos, es como si el pueblo hubiera descubierto sus deseos por la libertad y la necesidad de la vida colectiva. Para Proudhon, Bakunin y Bookchin, los ideales revolucionarios (anarquistas) pierden el sentido cuando se limitan solamente a una negación. Por lo tanto, lo que da significado a la lucha, además de la libertad, es la conquista del bienestar material, intelectual y moral (Kropotkin, P., 2007, p. 33). La praxis del anarquismo no es solamente colectiva, sino que se expresa en el individuo que desea buscar o mantener sus propias aspiraciones y voluntades, sin la figura del opresor, sin custodias y 
2 Aún no se puede afirmar si el carácter anárquico del trabajador del comercio informal de calle es el motivo por el cual permanece resistiendo en el espacio público, porque el estudio que analiza su comportamiento empíricamente está en curso en la investigación doctoral, pero hay indicios de que el desempleo no es lo único que conduce a los trabajadores callejeros a permanecer en esa actividad.

3 La traducción de la cita es nuestra. sin sujeción - motivado por un estilo de vida que desea resguardar sus derechos y libertad. El trabajador del comercio informal de calle parece traer en sí mismo el rasgo del anarquismo². la libertad, la autonomía y la resistencia, herramientas importantes para enfrentar a los opresores y ocupar el espacio público. Ese instinto político es lo que le diferencia de otros trabajadores informales, pues enfrentar la opresión con su propio cuerpo es algo potente que debe ser considerado para comprender su resistencia y permanencia en el comercio callejero (Salazar, G., 2003; Soto, H. de., 1996).

El artículo: "La mujer popular penquista en el trabajo independiente. Concepción I895-1905", de Gina Inostroza y Marcela Tapia (1993), trata sobre el trabajo independiente de las mujeres del comercio callejero de Concepción evidenciando el carácter de autonomía y libertad de las trabajadoras en su manera de enfrentar a las autoridades locales y lograr desarrollar su actividad en el espacio público. Según las autoras, entre 1895 y 1905 había cerca de 100 trabajadoras vendiendo comida en puestos del mercado y en la vía pública, cerca de la estación de ferrocarriles y alrededor del mercado. La actividad callejera ya combinaba la modalidad legal (con permiso municipal) y la ilegal (que transgredían las leyes de uso y ocupación del suelo urbano), siendo esa segunda la con mayor número de trabajadoras. En esa época el comercio informal de calle era sojuzgado por las autoridades locales y elites que no las querían en la ciudad, frente a eso no median esfuerzos para expulsarlas del espacio público. Entretanto, el asedio institucional no fue motivo para frenar esta actividad del comercio popular en la ciudad, el que resiste hasta hoy en las calles de Concepción. De ese modo, ¿de qué manera el trabajador del comercio informal de calle enfrenta los espacios de represión del poder y logra desarrollar su actividad en la ciudad y qué herramientas utiliza para permanecer en el espacio público? Los métodos para enfrentar los espacios de represión son parte de las maneras de hacer y garantías de trabajo que, conforme Michel de Certeau:

[...] constituyen las prácticas por las cuales los usuarios se reapropian de los espacios organizados por la técnica de la sociocultura $[\ldots]$ a través de operaciones casi microbianas que se proliferan en el seno de las estructuras tecnocráticas y alteran su funcionamiento por una multiplicidad de "tácticas" articuladas sobre los "detalles" del cotidiano $[\ldots]^{3}$ (2017, p. 41).

Los modos de proceder y la creatividad cotidiana son esquemas primordiales de la praxis callejera para enfrentar los procesos históricos de formación disciplinar de las instituciones, tanto en lo económico, lo político y lo jurídico, esenciales para asegurar el orden de la multiplicidad humana (Foucault, M. 20I4). En la lucha por mantenerse, es parte de la naturaleza del poder y la fuerza del Estado no 
soportar ninguna otra, ni superior, ni igual a la de él. "Una fuerza solo soporta la otra cuando es obligada [...], consecuentemente de un lado y del otro la guerra es permanente y la paz solamente una tregua" (Bakunin, 20 I I, p. 28). La suspensión del conflicto entre Estado y los que son contrarios a su modus operandi dependerá del nivel de conformidad de los que están contrarios a él, y es lo que explica el conflicto duradero entre poderes local y callejeros que no están dispuestos a retirarse del espacio público, lo que significa munirse de tácticas para enfrentar las estrategias del Estado y de la policía, en las garantías por los derechos sociales que incluyen el derecho a la ciudad (Henri Lefebvre).

El hecho de que los trabajadores del comercio informal de calle comprendan o intuyan sobre sus derechos sociales y la manera que utilizan su experiencia para enfrentar (de modo consciente o inconscientemente) diariamente los conflictos entre ellos y los poderes local, con el propósito de permanecer ejerciendo sus actividades callejeras en el espacio público, es una interrogante que atraviesa la discusión de ese artículo. Especialmente porque el comportamiento (o rebeldía) perdurable de los callejeros deriva, también, por desafiar las leyes urbanas y enfrentar la opresión a través de tácticas elaboradas en función de la coyuntura, como esas resultantes de las protestas sociales. Frente a tales circunstancias, las alternativas de interacción y reapropiación espacial encontradas por los trabajadores del comercio informal de calle se presentan en las formas de reorganización del espacio con el intento de garantizar su trabajo. Para eso, los trabajadores se adaptan rápidamente, crean un aparato de trabajo que permita desarrollar su labor. En el contexto de la crisis social, la combinación de factores y circunstancias son responsables por las transformaciones en los aparatos de trabajo y su "arquitectura efímera", cuyo material utilizado en su confección es esencial para exponer las mercaderías y facilitar la movilidad entre los callejeros, manifestantes y la policía.

De ese modo, el objetivo central de este estudio es mostrar las maneras de hacer (Certeau) que los trabajadores informales de calle del centro de Concepción emplean para resolver esas "nuevas" situaciones de conflicto para lograr ejercer sus actividades en el espacio público. Considerando que la búsqueda por el derecho a la ciudad es algo incansable en la vida de los trabajadores informales de calle, especialmente sobre cómo esas maneras han contribuido para la producción también de espacios efímeros y de qué forma son identificados en la ciudad de Concepción, particularmente en ese periodo de crisis social. 


\section{METODOLOGÍA}

Con base en el marco de referencias y objetivos planteados, este estudio se fundamenta, en buena parte, en las aportaciones teóricas de Michel de Certeau (2014), sobre el arte (maneras) de hacer, los usos, las estrategias y tácticas espaciales. Con la finalidad de comprender cómo y porqué razón el trabajador del comercio informal de calle resiste en un espacio público de una ciudad construida bajo un modelo tradicional y conservador, de vigilancia jerárquica (Foucault, 20।4); que produce malestar y una crisis de justicia social, con un diseño urbano que facilita el control de la ciudad y de sus habitantes; que es intolerante con la diversidad (Jane Jacobs, 20 I I), que margina las minorías y las masas. Habitar la ciudad hostil significa dotar maneras de hacer que, según Certeau, se dan a través de "mil prácticas por las cuales se reapropian del espacio organizados por medio de técnicas de producción socioespacial" (2014, p. 4I). La construcción de trayectorias de la producción del espacio sugiere un movimiento donde están, por una parte, las fuerzas formadas por el Estado y la economía y, por la otra, aquellos contrarios, que no disponen de bases para acumular beneficios, sino preparar el contraataque: las tácticas, como medio de garantizar una independencia resultante de una consciencia o instinto político en función de las coyunturas.

Los autores mencionados estudian aspectos de la ciudad y modos de habitar cuyos métodos de producción y apropiación dan luces sobre las tácticas de los trabajadores del comercio informal de calle configurando no solamente su carácter emancipatorio y libertario (Bakunin, Kropotkin) como también los métodos creados para perdurar en el espacio público. Esos procedimientos son los que se podría definir, considerando el contexto de la actividad callejera, como la manera de hacer, responsable también por la creación de una estructura provisional que conformará la producción del espacio efímero. Para entender el comportamiento (carácter) de los trabajadores del comercio informal de calle, se observa (in situ) las prácticas ocupadas por ellos que resultan en la reapropiación y permanencia en el espacio público. A partir de entonces, se eligió un análisis de esa observación con la idea de Michel de Certeau (2017, p. 44) sobre la "táctica de los practicantes" (en este caso los callejeros) según las prácticas cotidianas de los trabajadores del comercio informal, adaptando algunas de ellas de acuerdo con su realidad en el espacio público, como el caminar (circular), habitar el espacio (reapropiar, establecerse), producir el lugar (puesto de trabajo) y hablar (relación social).

A través de esa metodología, que incluye el registro fotográfico del "ambiente callejero" como herramienta de análisis, se pretende comprender la problemática presente en el cotidiano de los trabajadores del comercio informal de calle de Concepción. Con ese propósito, se plantea una reflexión sobre las maneras de hacer de los callejeros durante la crisis social chilena y las praxis que resultan en la reapropiación y producción de espacios efímeros, que culminará permanencias y conquistas de los derechos. 


\section{DISCUSIÓN \\ Fuerzas opuestas en la dis- puta por el espacio urbano: tecnócratas y callejeros}

Las acciones que emanan de las culturas sociales y dan como resultado la diversidad del espacio no siempre son aceptadas. La oposición de los tecnócratas contra determinados grupos de personas y las cosas que les representan son discriminadas, estigmatizadas y suprimidas. En sus proyectos de arquitectura y planificación urbana, lo que ellos hacen es ofrecer el mínimo de técnica al servicio de la organización de la vida cotidiana, someter a los habitantes a un poderoso sistema de opresiones y normas creadas por razones financieras, generando un espacio de conflictos y de obstáculo para el desarrollo político-territorial. Al revés de la diversidad, la tendencia es la homogeneización de usos y funciones de los espacios; las ciudades, en el ámbito del urbanismo, están propensas a no considerar en la arquitectura la microsociología (forma de habitar), ni la macrosociología (sociedad en su conjunto), como tampoco a involucrar la participación activa de los habitantes en todos los procesos de producción (Lefebvre, H., 200I, 1978). Esos proyectos son inclinados al fracaso, porque inevitablemente producirá ciudades de paisaje y comportamiento monótono y desigual (Jacobs, 20, p.I I).

Sin embargo, el dominio hegemónico sobre el espacio urbano producido en función de la economía global no es totalmente apropiado por la clase dominante, porque la ciudadanía históricamente siempre ha reivindicado su derecho de ocupar el espacio público (Lefevre, 200I). Justamente, se puede entender que las instancias de poder en el espacio urbano son combinadas, y no es concesión de un sólo grupo o una clase social, aunque las razones de cada uno sean legítimas, la conformación final del espacio construido es el resultado del valor que damos a él y es lo que va a condicionar la forma en que el poder se manifiesta (Salcedo, R. 2007, p. 7I). Una producción del espacio que podrá ser producto de los deseos que marcan la reproducción de las ciudades y de los lugares con toda su complejidad necesaria al mantenimiento de la vida. Los espacios de las ciudades presentan distintos niveles de realidad que van adquiriendo sentido en la medida que se producen los lugares en el (espacios). En ellos, las relaciones sociales determinan las formas de su ocupación a través de la apropiación y de reproducción de la vida.

Los argumentos de los agentes productores de la ciudad económica (empresarios, inversionistas del sector inmobiliario, gobierno), intencionalmente manipuladores de la opinión pública, diseminan la idea que: "los seres humanos son encantadores en pequeños grupos y nocivos en grandes grupos [...] por ese motivo, "la concentración de personas variadas debe ser evitada" (Jacobs, 201 I, pp. 243-244). Diferentemente del pensamiento tecnocrático y conservador, las ciudades exitosas son aquellas que contienen componentes de la diversidad necesarios y favorables tanto económica como socialmente. Zygmunt Bauman cita una definición de Richard Sennett que dice: una ciudad "es un asentamiento humano en que los extraños tienen probabilidades de conocerse" (2003, p. 102). Bauman considera que la probabilidad de que los extraños se encuentren como extraños y continúen siendo extraños después del primer encuentro es factible. Posiblemente, este primer encuentro será en 


\section{La producción efímera del espacio en la ciudad de Concepción durante la crisis social.}

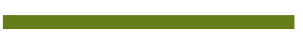

Figura 1 Barros Arana. Fuente: Mônica de Souza. realidad un desencuentro - "el encuentro entre extraños es un acontecimiento sin pasado y sin futuro"' (2003, p. 104). De ese modo, el momento del encuentro debe ser acertado, no habiendo espacio ni para sondear, cometer equívocos o la ilusión de otra oportunidad. Asimismo, se espera que el otro extraño sea recíproco y empático al primer acercamiento, porque de ese encuentro se hará la ocasión. Bauman y Certeau creen que las oportunidades para la vida urbana dependen de la habilidad especial del individuo. En el caso del trabajador informal de calle, es quien será favorecido por su experiencia social desarrollada cotidianamente en la calle, donde las relaciones sociales entre los propios callejeros (acuerdos, empatía, generosidad y competencia); entre ellos, sus clientes potenciales y los antiguos (seducidos) proporcionan una experiencia favorable a la creación y mejoramiento de las tácticas espaciales con intención de aumentar su capacidad y resistencia en el espacio urbano.

La capacidad de convivir con las diferencias, señala Bauman: "es un arte que, como todas las artes, requiere estudios y ejercicio" (2017, p. I14). Conforme Certeau, el arte de hacer o las maneras de hacer están intrínsecamente basadas en la creatividad cotidiana y constituyen infinitas prácticas de las cuales los usuarios se reapropian del espacio organizado por los tecnócratas y productores culturales. La noción de reapropiación del espacio significa la reapropiación para un uso diferente al original.

Tal concepto nombra el resultado de las prácticas del trabajador del comercio informal en el espacio urbano, lo que ocurre a partir de la reapropiación del espacio urbano con la finalidad de transformarlo en un comercio popular al aire libre, resultando en un nuevo espacio. Para producir ese espacio los trabajadores callejeros (ambulantes, con puestos fijos, artesanos y artistas) crean una estructura temporal que durará 


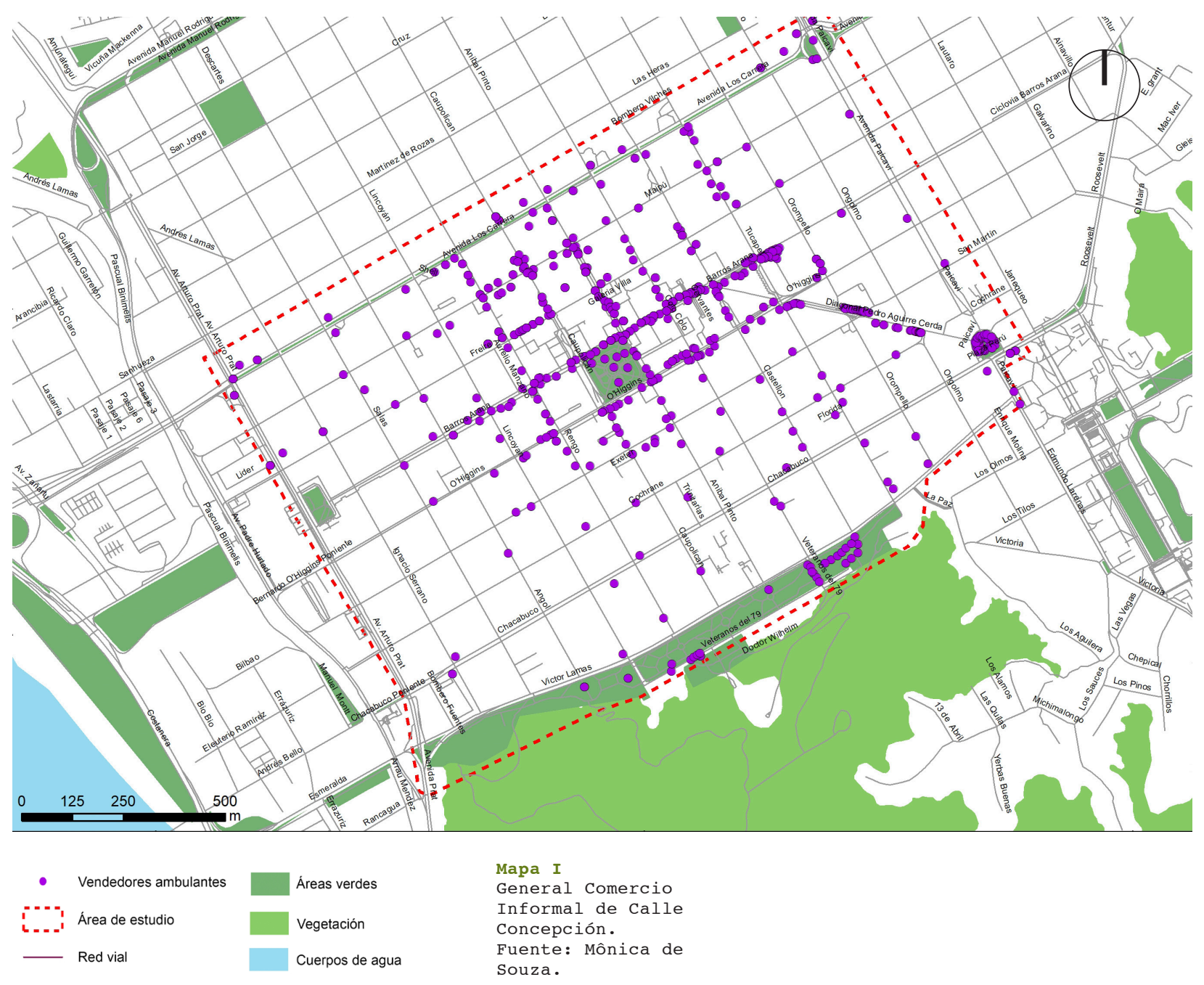

4 El objetivo de esos mapas en este estudio, particularmente, no es profundizar sobre el tipo o estructura del comercio informal de calle, sino mostrar el fenómeno en términos de ocupación espacial en Concepción, así como evidenciar los espacios de mayor concentración de esa actividad en el centro; lo que corrobora con la información sobre el gran número de trabajadores establecidos en determinadas zonas de la ciudad.

5 La intervención material se da a partir de quioscos y carritos movibles que presentan un tipo de diseño estándar autorizados por el poder local a los trabajadores informales con permiso municipal mesas, cajas de cartón y plástico, carritos de supermercado y de construcción civil, bicicleta, tenedores, cuerdas, plásticos, toallas, telas de género para extender sobre el piso, canastros, baldes, bolsas entre otros. el mismo tiempo del funcionamiento del comercio y servicios de la ciudad. En el caso de Concepción, la reapropiación del espacio urbano en mayor escala sucede en el centro de la ciudad [Mapas I y 2] $]^{4}$ con las intervenciones ${ }^{5}$ : A) material, B) físico: cuerpo - los trabajadores ilegales conocidos como coleros ${ }^{6}$. En la ciudad de Concepción el número de trabajadores del comercio informal de calle es más significativo en el paseo Barros Arana [Figura I], plaza Independencia, paseo Anibal Pinto, calle Freire, Maipú, calle Diagonal Pedro Aguirre Cerda y plaza Perú, y C) artistas.

El ejercicio de la actividad del comercio informal es permitido solo a 385 personas autorizadas, según el Acuerdo núm. 69078-2007, del Consejo Municipal de Concepción, para la Venta de Productos en Vía Pública y de la Ley núm. 18.695. Sin embargo, el número de trabajadores del comercio informal de calle ilegal (sin permiso) es visiblemente superior a la cantidad de los trabajadores con permiso, aunque no existan datos oficiales para corroborarlo. El número superior de callejeros en el espacio indica el tipo de ocupación espacial y de diseño sobre la calle. En general los callejeros en 


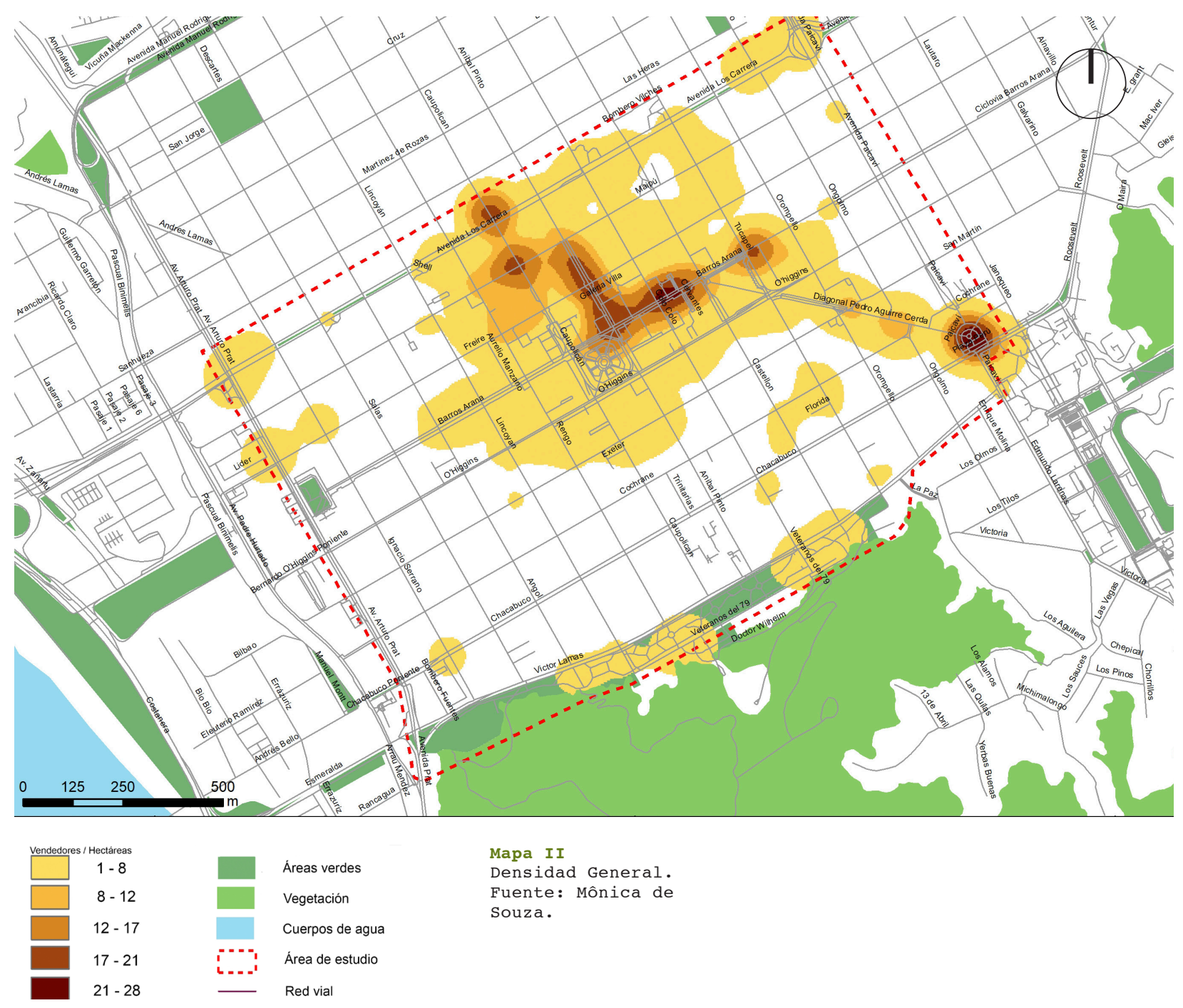

6 Colero es el callejero informal ilegal, que trabaja en las ferias libres o en centro de la ciudad sin autorización para ejercer la actividad. Generalmente los coleros se instalan en el borde de la ferias o al lado del trabajador con permiso. Estos trabajadores informales de calle son aquellos que pueden utilizar o no una superficie de apoyo o aparato para exponer sus productos. muchas veces utilizan sus propios cuerpos para cargar y mostrar los productos. Colgador de cajas o colgadores de paraderos son trabajadores que comercializan sus productos en los paraderos y dentro de los microbuses. situación ilegal ocupan el costado de la vereda cerca de la puerta de entrada de las tiendas, pues ellos sujetan sus mercaderías en general pequeñas y en menor cantidad. Las personas que venden ropa, pañuelos, calcetines, gorros, etc., ocupan el centro de la vereda y cerca de las esquinas para escapar de la policía - que al llegar produce un "movimiento de ola", pues el primer callejero, al constatar la llegada de los uniformados, logrará avisar a los demás, que van a escapar a tiempo. Como en el mar, la "ola puede ser más fuerte o más débil", no importa, pues ambas van a ir y volver a la calle conforme el nivel de opresión de la policía.

El trabajador del comercio informal de calle, especialmente el ilegal, trabaja todos los días bajo presión e inminencia de la opresión: mientras atiende el cliente, mira todos los movimientos alrededor y logra percibir desde la presencia de los uniformados hasta la presencia de los fiscales municipales. Frente a la amenaza, la táctica ocupada por el trabajador será elegida de forma oportuna y bien preparada para asegurar su independencia delante de las circunstancias [Figura 2]. "El cálculo 
Figuras 2 y 3

Plaza

Independencia,

Concepción.

Fuente: Mônica de

Souza. bien hecho será una victoria sobre el tiempo" (Certeau, 20 I4, p. 46). En el cotidiano de la calle las tácticas son relativas, no obedecen a un patrón o lugar. Al revés, la estrategia es más previsible. Por lo tanto, el trabajador del comercio informal de calle está preparado para resistir y enfrentar el conflicto [Figura 3], aun cuando el callejero no esté ocupando el espacio, su marca estará allí. El trabajador del comercio informal reapropia el espacio porque probablemente él refuta la propiedad, menos aún cree en el Estado o en la protección de la policía. El espacio urbano no es un espacio neutral, existe una especie de mapa social que separa las clases sociales, las que organizan el espacio reactivando enormes transformaciones urbanas. Y la organización social también reproduce espacios de identidad que pueden influenciar directamente en las praxis colectivas (Oyón, J. 2008, p. 114).

Las primeras cinco semanas de protestas en Chile cambiarán la rutina de sus principales ciudades. El entrelazamiento y yuxtaposición social está latente. Durante las manifestaciones, las calles del centro de Concepción cedieron lugar a un ambiente masivo de chilenos politizados oprimidos por las Fuerzas Especiales de Carabineros (FF.EE.), generando indignación y un ambiente de conflicto [Figura 4]. Bajo estas circunstancias, el horario de funcionamiento del comercio fue alterado, algunas tiendas inclusive quedarán días con sus puertas cerradas. Las fachadas de los edificios comerciales fueron cubiertas por placas de maderas, metálicas [Figura 5] y rejas de protección,
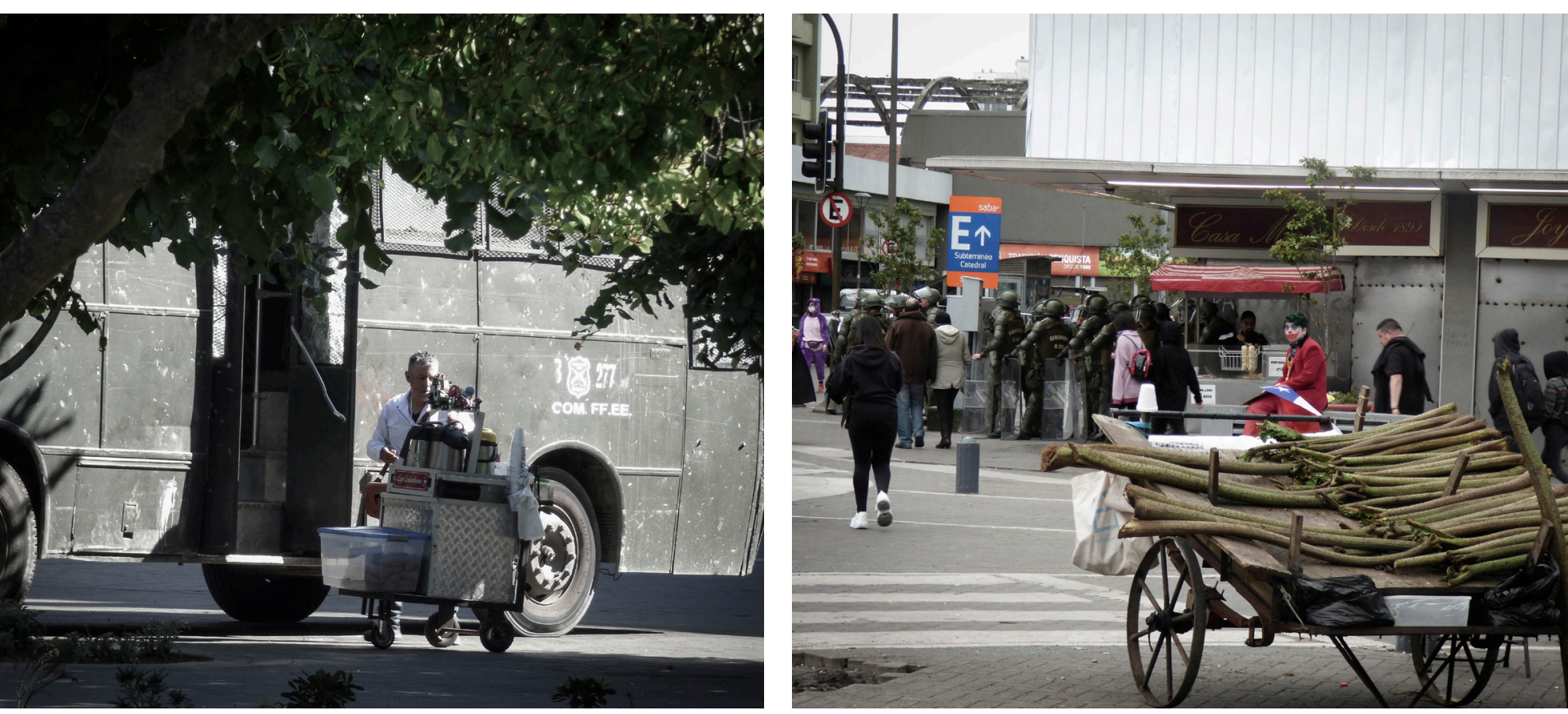


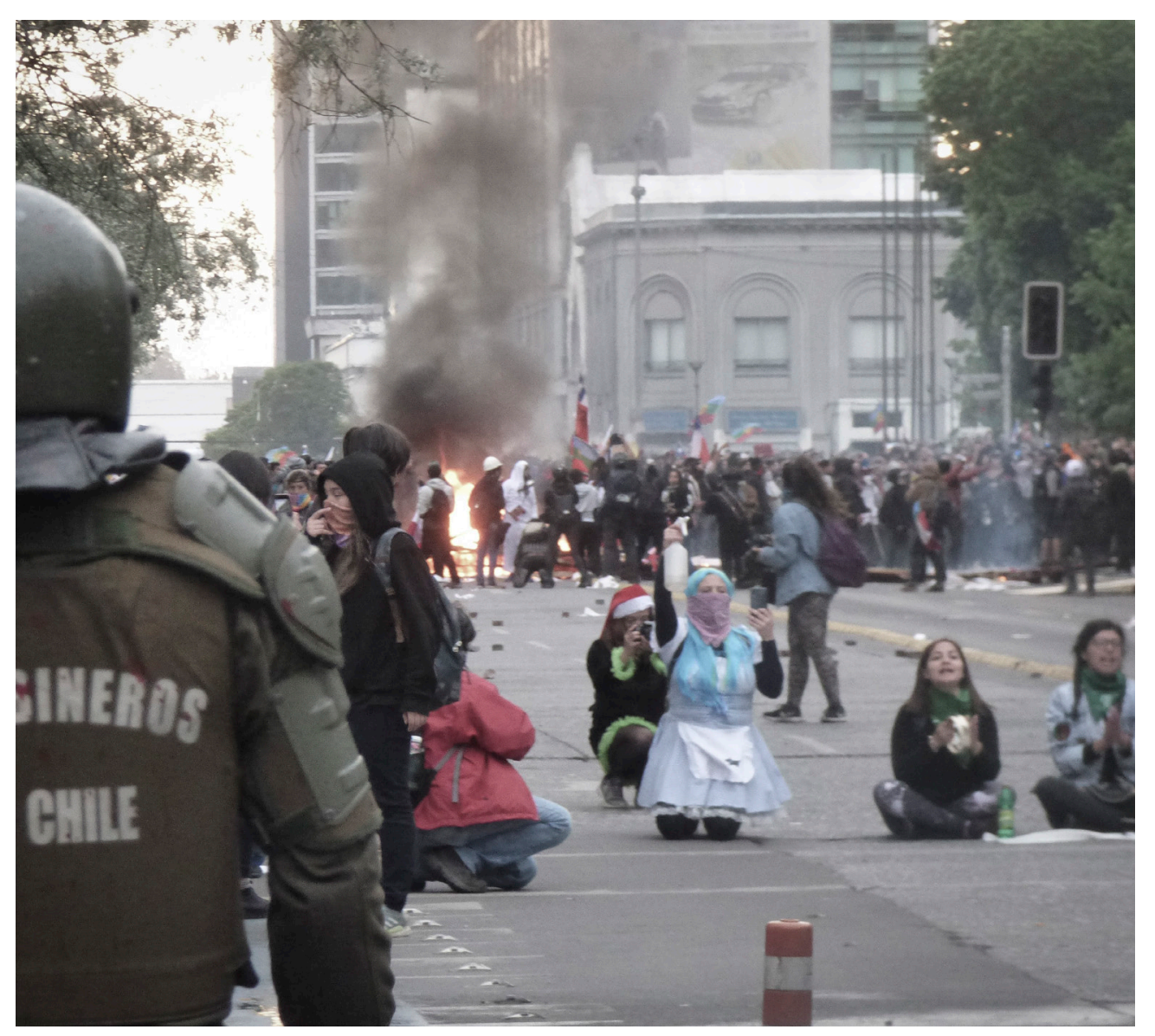

Figura 4

Plaza Independen-

cia, Concepción.

Fuente: Mônica de

Souza.

Figuras 5

Puertas metálicas en tienda de Paseo Barros Arana. Fuente: Mônica de Souza.

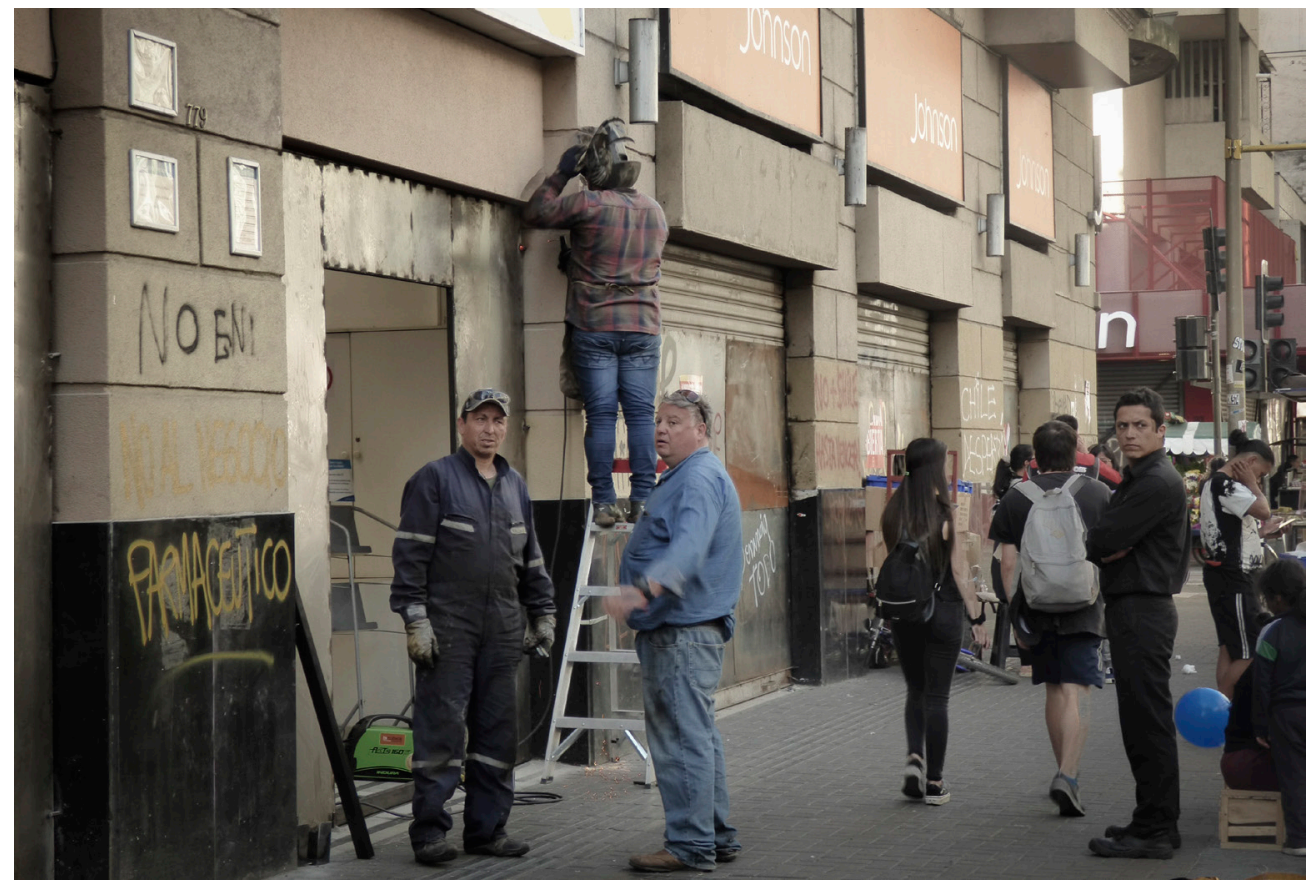




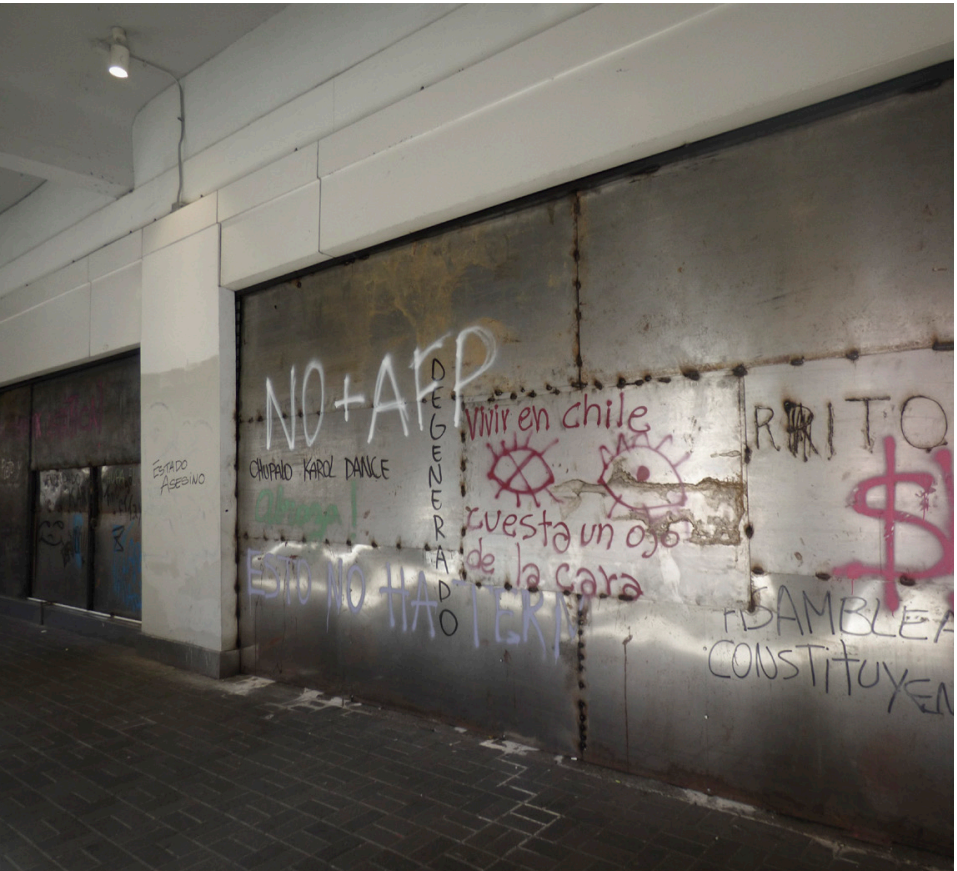

Figuras 6 .

Tienda blindada en

Paseo Barros Arana.

Fuente: Mônica de

Souza.

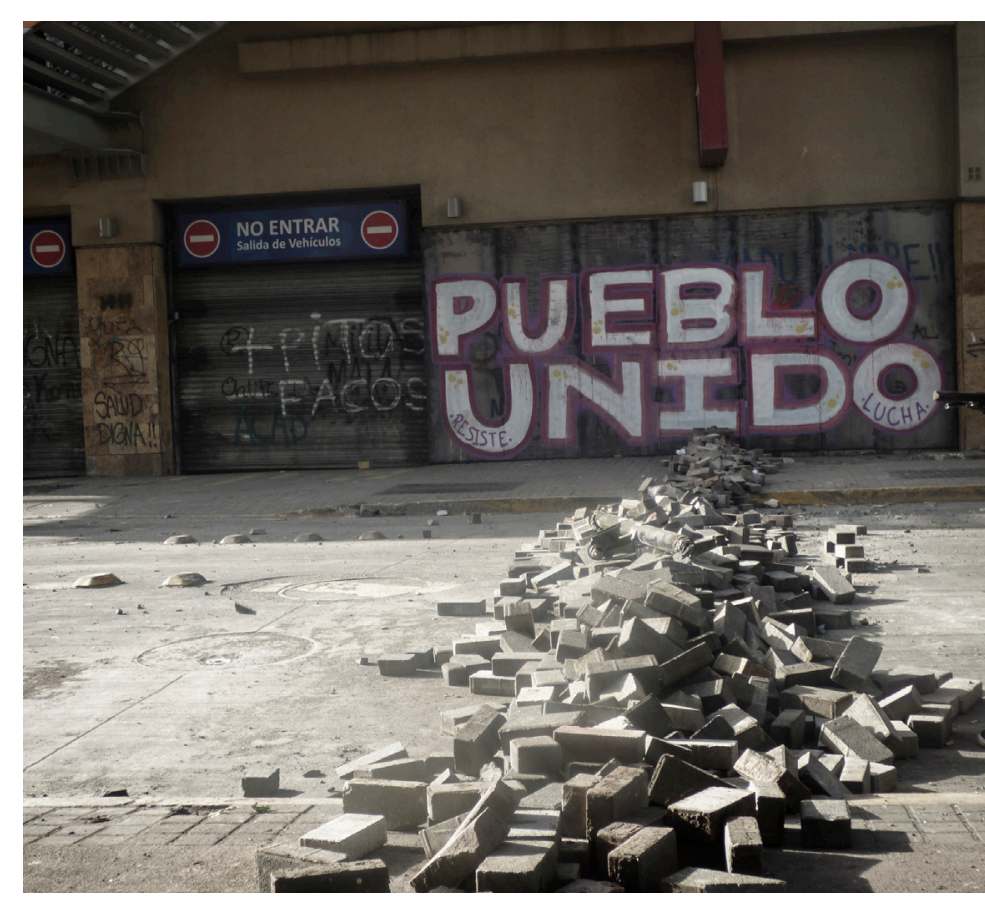

Figura 7

Graffitis y barricada

en la fachada del

Mall del Centro Av

Bernardo O'Higgins.

Fuente: Mônica de

Souza.

infringiendo la Normativa Antisísmica, las recomendaciones del Cuerpo de Bomberos y la Ordenanza General de Urbanismo y Construcciones de Chile. Asimismo, los comerciantes siguen revistiendo las fachadas [Figura 6] mediante consentimiento del gobierno local, bajo la justificación de proteger sus negocios de las acciones de los manifestantes, produciendo así, una especie de arquitectura efímera de miedo, del caos (analogía al paisaje el miedo de Yi-Fu Tuan, 2005). El nuevo elemento arquitectónico tiene la función de tapar las vitrinas, puertas y ventanas que dan accesos a los edificios, reservando una pequeña entrada y salida. Las inmensas fachadas de metal se han convertido en pizarras, en páginas de un cuaderno de memorias y pensamientos. Las paredes de los edificios del centro reciben el mismo tipo de intervención, el arte de la revolución popular: los grafitis, afiches y pinturas [Figura 7]. Toda la imagen de la ciudad de Concepción es efímera - los revestimientos de las veredas, las extrañas y exageradas fachadas metálicas y de madera, el mobiliario de la plaza y los senderos improvisados cubiertos por las mercaderías de comercio informal. Mientras el comercio establecido se mantiene cerrado o funciona de modo 
intimidado detrás de las rejas y puertas de protección, los trabajadores del comercio informal de calle comparten con los manifestantes la lucha y al mismo tiempo venden sus mercaderías [Figura 8], abasteciendo las marchas con kit protesta: banderas, vuvuzelas y silbatos, agua, sándwiches, caramelos, lápiz, tabacos y tintas para escribir en los cartones. Familias enteras de migrantes ecuatorianos venden sombreros, bandanas y pañuelos contra las lacrimógenas de todos los colores y tamaños, y los haitianos comercializan caramelos, galletas y chocolates. Esa es una gran oportunidad de garantizar alguna ventaja. Muchos callejeros que vendían frutas y verduras en las esquinas tomadas por los conflictos entre manifestantes y la policía se desplazaban para calles más tranquilas del centro, donde seguramente llegará la "caserita" (cliente). Otros cambian sus productos habituales por aquellos de mayor demanda en las marchas (agua, kit protesta), incluso algunos trabajadores informales que lavan autos en las calles aprovecharán la oportunidad para vender los kits. Los trabajadores informales de calle acompañan el trayecto de la marcha ofreciendo los productos, pues el paseo Barros Arana se ha convertido en un lugar del conflicto, como siempre ha sido, aunque de forma distinta.

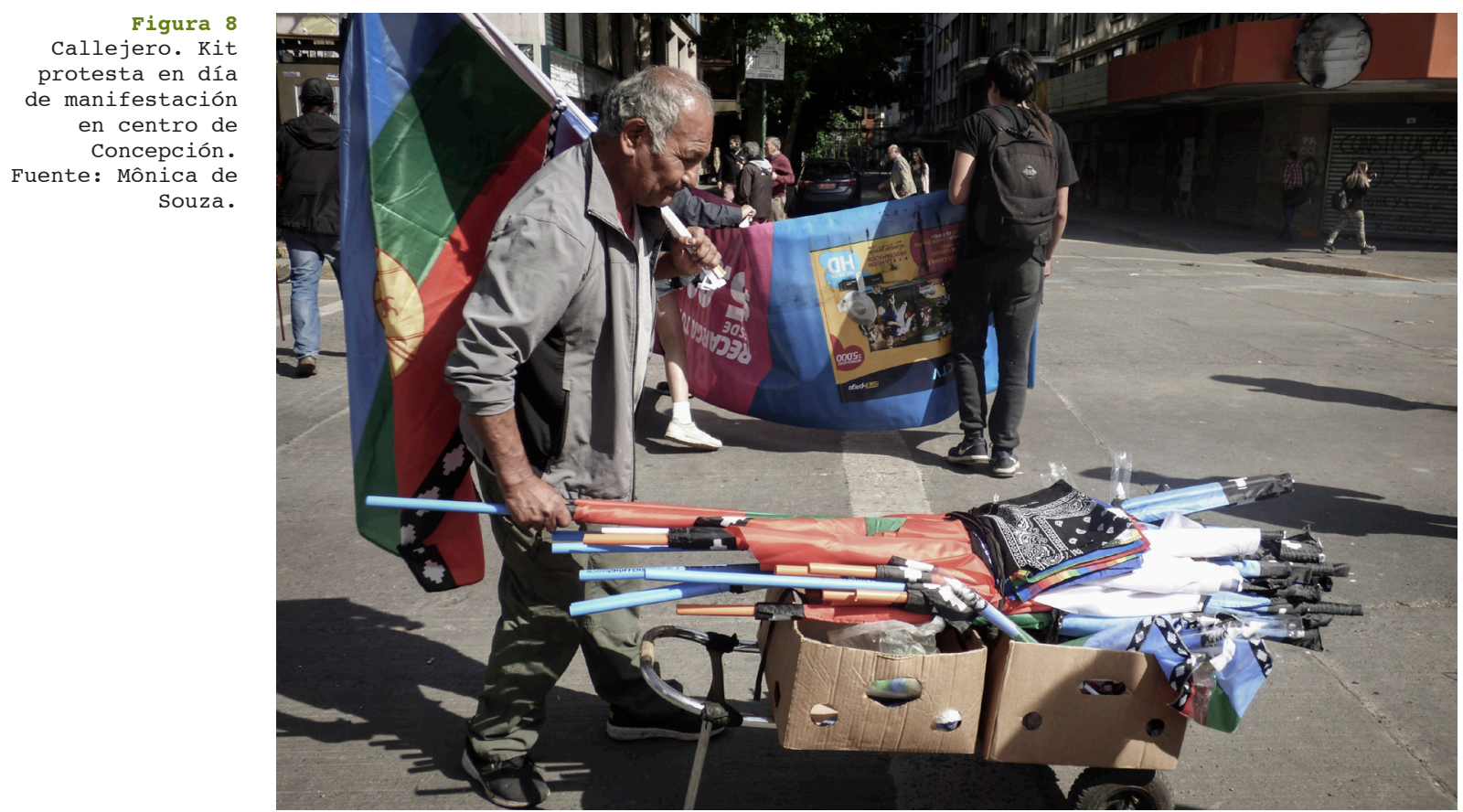




\section{CONCLUSIONES}

AS / Vol. 38. No57 / ENERO 2020 // ISSN impresa 07 | 6-2677 / ISSN digital 0719-6466

CONCEPCIÓN: EL TRABAJADOR DEL COMERCIO INFORMAL DE CALLE.

La producción efímera del espacio en la crisis social.

Mônica Virginia de Souza
Kevin Lynch, al tratar el tema legibilidad del paisaje urbano, indica "la facilidad con que pueden reconocerse y organizarse (la ciudad) en partes de una pauta coherente [...] conexa de símbolos reconocibles" (2006, p.I I); que significa un espacio con símbolos identificables y legible en los barrios, los sitios y las sendas se conectan en un sentido global, esa es la "estructura" de ciudad ideal. La crisis social chilena ha cambiado el cotidiano y la imagen de la ciudad, ahora son las protestas quienes dictan las reglas para su funcionamiento: antes, durante y después de las marchas. En Concepción, el trayecto de los manifestantes parte del Arco de Medicina de la Universidad de Concepción (UdeC) recorriendo las avenidas Bernardo O'Higgins, Paicaví y en el barrio cívico deteniéndose en la Plaza Independencia (en el centro de la ciudad), corazón de las manifestaciones. Es interesante la organización espacial y la logística de la jornada de protestas que dividen en tramos el espacio urbano: la Plaza Independencia (de Armas) es el punto para la escena social, el espacio del teatro y del púlpito de la masa politizada para exponer sus críticas y pensamientos. En todos los sitios del centro están los trabajadores del comercio informal que, desde el siglo $X I X$, reivindican su derecho a la ciudad. Esa batalla es diaria y nadie está dispuesto a retroceder, ni los que luchan por libertad, dignidad y justicia, y ni los que están dispuestos impedir que eso suceda. En ese paisaje la legibilidad y legitimidad de la ciudad es clara, la praxis de su producción demuestra nítidamente el objetivo de lucha por derechos. En ese contexto, la producción efímera de los trabajadores del comercio informal de calle representa no solamente la idea sino la certeza que pertenecen a la ciudad y a esos lugares. Hoy en Concepción, en tiempos de crisis social, las expresiones y la producción de lugares efímeros provoca capas sobrepuestas, las que dan como resultado un gran proyecto temporal que simboliza las luchas por los derechos y por las libertades. El espacio efímero producido por los trabajadores del comercio informal de calle conlleva a indagaciones relativas al real significado por detrás de la legibilidad de la ciudad tecnocrática. Por lo tanto, la vida en la ciudad, la humanización de espacio urbano (Gehl, J. 20/3), en sentido stricto sensu, podría propiciar más oportunidades de las que ofrece su planificación. De ese modo, la intención de este artículo es proponer una reflexión sobre otras cuestiones que permean el "ideal de ciudad" a partir de prerrogativas que consideran la experiencia real de deseos individuales y colectivos. 


\section{BIBLIOGRAFÍA}

BAKUNIN, M. O princípio do Estado e outros ensaios. São Paulo: Hedra. 2011.

BAKUNIN, M. Revolução e liberdade. Cartas de 1845 a 1875. São Paulo: Hedra. 2010.

BAUMAN, Z. Modernidad líquida. Fondo de Cultura Económica. México. 2003

$\mathrm{BOOKCHIN,} \mathrm{M.} \mathrm{Anarquismo,} \mathrm{crítica} \mathrm{e} \mathrm{autocrítica.} \mathrm{Primitivismo,} \mathrm{indivi-}$ dualismo, caos, misticismo, comunalismo, internacionalismo, antimilitarismo e democracia. São Paulo: Hedra. Traducción: Felipe Corrêa y Alexandre B. de Souza. 2011.

CERTEAU, M. de. A invenção do Cotidiano. 1. Artes de fazer. 22ª . Ed. $2^{\text {a }}$ reimpresión. Petrópolis: Ed. Vozes. 2014.

FOUCAULT, M. Vigiar e punir. Nacimento da prisão. 42a . Ed (2017). Rio de Janeiro: Ed. Vozes. 2014.

GEHL, J. La humanización del espacio urbano. La vida social entre los edificios. $2^{a}$. ed. Reimpresión, 2017. Barcelona: Ed. Reverté.

INOSTROZA, G. eTAPIA, M. La mujerpopularpenquista en el trabajo independiente. Concepción 1895-1905. 1993, Artículo recuperado en: https:// www.semanticscholar.org/paper/La-mujer-popular-penquista-en-el-trabajo-Inostroza-Tapia/a755edbf4c513b5b714f3a535e11a095a81b7c37

JACOBS, J. Morte e vida de grandes ciudades. $7^{a}$. reimpresión. São Paulo: Ed. Martins Fontes. 2011.

KROPOTKIN, P. (2010). O princípio anarquista e outros ensaios. São Paulo: Hedra. 2010.

LEFEBVRE, H. De lo rural a lo urbano. Las relaciones entre el campo y la ciudad a la luz crítica de la filosofía y la sociología marxista. Barcelona: Ed. Península. 1978.

LEFEBVRE, H. La producción del espacio. $1^{\text {a }}$. ed. Madrid: Ed. Capitán Swing. 2013

LEFEBVRE, H. O direito a Cidade. 2a . ed. São Paulo: Centauro. 2001.

LYNCH, K. La imagen de la ciudad. $7^{\text {a }}$. ed. Barcelona: Editorial Gustavo Gili, SL. 2006.

OYÓN, J. L. La quiebra de la ciudad popular. Espacio urbano, inmigración y anarquismo en la Barcelona de entreguerras, 1914-1936. Barcelona: Ediciones del Serbal. 2008.

PROUDHON, P. ¿Qué es propiedad? 2005. 1ª . ed. Buenos Aires: Libros Antares. Recuperado de: https://www.marxists.org/espanol/proudhon/ prop/index.htm

RICOUER, P. Finitud y culpabilidad. Madrid: Taurus Humanidades. 1991.

RUIZ, C. E. La política en neoliberalismo: experiencias latinoamericanas. Santiago de Chile: Ed. LOM. 2019.

SALAZAR, G. Ferias libres: espacio residual de soberanía ciudadana. Santiago: Ediciones Sur. 2003.

SALCEDO, R. La lucha por el espacio urbano. En Segovia, O. (editorial). Espacio público y construcción social. Hacia un ejercicio de la ciudadanía, 2007. pp 68-77. Recuperado de: https://derechoalaciudadflacso. files.wordpress.com/2014/01/rodrigo-salcedo-la-lucha-por-el-espacio-urbano.pdf

SENNETT, R. Carne e pedra. O corpo e a cidade na civilização ocidental. $4^{a}$.ed. Rio de Janeiro: Ed. Best Seller. 2016.

SOTO, H. de. El outro Sendero. 4a. Ed. Buenos Aires: Editorial Sudamericana. 1992.

TUAN, Yi-Fu. Paisagens do Medo. São Paulo: Ed. UNESP. 2005. 